\title{
A SUSTENTABILIDADE COMO ELEMENTO CENTRAL DA REABILITAÇÃO: A RESPOSTA AOS DESAFIOS EUROPEUS
}

\author{
1. $^{\circ}$ Ana Ferreira Ramos ${ }^{1}$ \\ ana ramos@ipcb.pt \\ 3. ${ }^{\circ}$ Cláudia Peres Almeida ${ }^{2}$ \\ almeida.claudiaperes@gmail.com
}

\author{
2. ${ }^{\circ}$ J. Mendes da Silva ${ }^{2,3}$ \\ raimundo@dec.uc.pt \\ 4. ${ }^{\circ}$ Catarina Mouraz ${ }^{2}$ \\ catarinamouraz@hotmail.com
}

\section{ÁREA: REABILITÇÃO E LEGISLAÇÃo}

\section{Resumo}

A Estratégia 2020 da Europa define desafios relacionados com a reabilitação do ambiente construído, assumindo a sua importância para o consumo de energia e emissões de gases com efeito estufa. Neste sentido foram definidas diversas políticas, em vários setores da economia, com vista a atingir o objetivo de redução em $20 \%$ das emissões, redução em $20 \%$ do consumo energético e aumento da produção de energia com recurso a energias renováveis em $20 \%$.

A sustentabilidade deve estar alinhada com os objetivos estratégicos e políticos, neste sentido importa incorporar estes objetivos em sistemas de avaliação da sustentabilidade, nomeadamente no setor da reabilitação de edifícios. No âmbito deste trabalho foram analisadas as políticas europeias e portuguesas em relação à reabilitação do parque edificado, identificando as exigências e metas que tenham implicações ao nível do projeto, em alguns casos sendo condicionantes para o acesso a fundos europeus.

A partir da identificação das implicações destas políticas nas intervenções, foi definida uma metodologia simplificada de avaliação da sustentabilidade na reabilitação, com a definição de critérios de avaliação. Estes critérios incorporam as exigências das políticas, revelando-se uma ferramenta que responde, não só às exigências de qualidade ambiental, social e económica dos edifícios, mas também as prioridades políticas de âmbito nacional.

Palavras-chave: Estratégia Europa 2020

Sustentabilidade na Reabilitação

Modelo de Avaliação da Sustentabilidade

\footnotetext{
${ }^{1}$ Instituto Politécnico de Castelo Branco, Escola Superior de Tecnologia, Av. do Empresário, 6000-767 Castelo Branco, Portugal

2 Faculdade de Ciências e Tecnologia da Universidade de Coimbra, Rua Sílvio Lima, Pólo II da Universidade de Coimbra, 3030-790 Coimbra, Portugal

${ }^{3}$ LAETA-ADAI, Departamento de Engenharia Civil, Universidade of Coimbra, Portugal
} 